\title{
A Monstrous Philosophy of Emotions Luke Currie*, Philosophy
}

\begin{abstract}
Through an analysis of Søren Kierkegaard's Diapsalmata from the first volume of Either/Or, a work which exhibits strikingly contemporary ways of thinking, this paper seeks to uncover the complex and paradoxical ways in which emotions inhabit a person. The urge to explicate the complexity of emotions arose from the author's dissatisfaction with the rudimentary schematic used in daily life wherein emotions are categorized and hastily rationalized, misconstruing their greater complexity. Emotions are often irrational, contradictory, etc., and must be considered on those terms. Thus, concession of paradox is vital in order to think through contradictory states of emotions. An aphorism from Pascal states that we are nothing but "lies, duplicity, and contradiction." With this idea in mind, the essay proceeds to argue that the use of pseudonyms to create contradictions within Kierkegaard's Diapsalmata show the Diapsalmata functioning as a "monstrous" philosophy of emotions. What is meant by "monstrous" differs from the colloquial use of the term and the essay's particular usage is discussed with reference to Socrates and Typhon in Plato's Phaedrus. The paper claims that Kierkegaard's thought as a whole is "monstrous" in the dissonance of the religious, comedic, ethical, ironic, and aesthetic stages he constructs in his broader philosophy. The monstrous philosophy of emotions developed from the Diapsalmata is argued to have a "prefatory weight" on the question of Being, i.e. "why are there beings instead of nothing?" The way in which different emotions preface this question is briefly discussed. The conclusion emphasizes the importance of understanding the complexity of emotions philosophically.
\end{abstract}

"Talk about humility gives occasion for pride to the proud and humility to the humble. Similarly, skeptical arguments allow the positive to be positive. Few speak humbly of humility, chastely of chastity, dubiously of skepticism. We are nothing but lies, duplicity, contradiction, and we hide and disguise ourselves from ourselves” (Pascal, 240).

* Luke Currie is a junior philosophy major. His particular interests in philosophy concern questions in the subfields of ontology and ethics. After completing his undergraduate studies, Luke hopes to attend a graduate school that shares his research interests. Along with his fondness for philosophy, he listens to, plays, and writes music. He also enjoys experimental comedy, and draws in his spare time. Please direct correspondence to lcurrie7@uoregon.edu. 
Despite the radical tone of Pascal's claim that we solely consist of "lies, duplicity, and contradiction," his hyperbolic insistence that we are nothing but is a poetic device indicating his claim should not be taken literally. One might then dismiss this as one of Pascal's characteristically gloomy formulations and deem it unworthy of being taken seriously. Yet to do this would evade the very real force of his claim: to what degree do I disguise myself from myself? Am I merely a sum of contradictions masquerading as a quasi-coherent self? Is not the self which I present to the world ever-changing, duplicitous, multiplicitous? Is not this self, too, a fiction? One created out of an inability to account for my contradictions? The range of questions which erupt from Pascal's aphorism must be circumscribed if one wishes to attain anything like an answer to them. One way in which we most overtly contradict ourselves is in and through our emotions. Such contradictions are monstrous insofar as the self which experiences these contradictory emotions is a whole self-made of discordant parts, namely differing emotional states, rather than a whole comprised of harmonious, non-contradictory parts. Pascal addresses the issue of a contradictory self succinctly in his aphorism while Søren Kierkegaard "performs" it in his Diapsalmata and in his works in general. This preliminary reflection inspired by Pascal's aphorism leads me to consider Kierkegaard's Diapsalmata as a monstrous philosophy of emotions. Before addressing the relationship between the different moods which appear in the Diapsalmata, I shall provide some context for that work.

The authorship of Kierkegaard's Either/Or is obfuscated by pseudonyms. Either/Or is, as discussed in its preface by Victor Eremita, Kierkegaard's first pseudonym, a collection of essays, letters, and fragments from two authors whom Eremita discovered. He names them A and B, respectively. Author A's writings are inclined toward the "aesthetic" while Author B is inclined toward the "ethical." Either/Or is principally a work which attempts to put these two authors and the aesthetic and ethical they represent in dialectical tension. Along with these three pseudonyms, Author A discovers a diary of a man named Johannes, giving us a fourth pseudonym. Eremita embeds this diary within A's own works, seeing that Johannes' diary shares a similar aesthetic comportment to A's own writings and believing Author A and Johannes to be the same person. Yet, of course, all of these authors are just Kierkegaard playing different roles. Through the power of the pseudonym and the obfuscation of authorship, Kierkegaard takes on the roles of a discoverer and editor of unknown works, an aesthetic writer of melancholic poetry and philosophy, a judge who rebuts the aesthetic writer's stance in favor of the ethical, and so on. While Pascal uses poetic hyperbole to confront man's contradictions, Kierkegaard textually "performs" these contradictions through the writings of the pseudonyms. These contradictions only begin to show when considering Kierkegaard's pseudonyms in relation to each other--any particular pseudonym's writing is self-consistent.

The internal conflict of Either/Or gives rise to dialogical relationships between its fictional authors. As mentioned above, Author A and Author B represent a tension between the aesthetic and the ethical. Author B is a judge whose writings are largely clinically written moral condemnations of the amoral, existential, and emotional writings of Author A, who claims to be a poet. he two authors' writings support worldviews which are in tension with one another. Kierkegaard's different "stages of experience" (namely the aesthetic, the ethical, and the religious 
stages) operate with a similarly crucial tension: the aesthetic is always in conflict with the ethical as the ethical is always in conflict with the religious. The distinctions between these stages, however, are not entirely rigid as they inhere in one another to varying degrees. The tension of the three stages gives rise to two liminal stages: The ironic stage arises between the tension of the aesthetic and the ethical, and the comedic stage arises between the ethical and the religious. One does not solely occupy distinct stages at distinct times but rather bleeds between them and often occupies various stages simultaneously. Thus, like Pascal's conception of the contradictory, selfdeceiving self, Kierkegaard presents a self in contradiction with itself, a self which can occupy and experience stages of experience which are at odds with one another.

Kierkegaard seems to have intended the whole of Either/Or to act as an extensive thought experiment. It places the different authors' writings in tension with one another and refuses to resolve the tension, inviting engaged readers to reconcile the views in tension and seek their own conclusion. Given the structure of the text, Kierkegaard shows himself as a contradictory self by occupying these different stages through the pseudonyms. This calls into question the degree to which Kierkegaard himself embodies each of the authors of the text and, furthermore, which authors originated from his own genuine experience and which, though still originating from him, are the product of ingenious artifice. Around the time he was writing Either/Or and had a falling out with the love of his life, Regine, he declared that the aesthetic was ultimately his "element." In a letter to his friend Boesen, he said, "This matter [between Regine and I] ... has two sides, an ethical and an aesthetic... The aesthetic is above all my element. As soon as the ethical asserts itself, it easily gains power over me. I become a quite different person, I know no bounds for what my duties may be, et cetera" (Garff, 205). With this in mind, one approaches Either/Or differently, particularly Author A's aesthetic writings. Of A's writings, the Diapsalmata are perhaps the most affecting and devastating. The work is a brief collection of disordered aphorisms, which are pithy statements that exist somewhere between the concision of an axiom or maxim and the evocative immediacy of a poem. Kierkegaard could not have created the aphorisms in the Diapsalmata solely through artifice--these aphorisms must have come from lived experience. With this initial impression of the work and the fact that Kierkegaard himself, at least around the time of Either/Or's genesis, claimed he favored the aesthetic above all else, one can say with some confidence that the Diapsalmata is more or less directly from Kierkegaard himself, masked by the pseudonym attached to it and a product of the pseudonym which gives way to the very expression of his experiences. A pseudonym both obscures and makes clear. From here it would be best to interrogate the relationship between the aphorisms in the work and begin to develop a philosophy of emotions.

The moods of the Diapsalmata oscillate from bored to ecstatic; from melancholic to comedic; from nihilistic to life-affirming. The contradictory nature of the work initially confuses the reader. Author A himself occasionally thematizes contradiction in the Diapsalmata. In one instance, A says, "There are, as is known, insects that die in the moment of fertilization. So, it is with all joy: life's highest, most splendid moment of enjoyment is accompanied by death" (Kierkegaard, 20). Here the highest experiences in life are met with their contrary, if taken literally. This may also be taken metaphorically. One does not usually die after experiencing the enjoyment A alludes to, but 
perhaps one feels as though one had died in the fallout of this moment of supreme joy--that a supreme melancholy appears in the passing moment of supreme joy is undeniable, and that these opposites result from the same experience and differ only in temporal succession is crucial. On a particular experience, which showcases this general emotional movement, in Kierkegaard's notes for Either/Or, he says, "I have just now come from a gathering where I was the life of the party; witticisms flowed out of my mouth; everybody laughed, admired me---------but I left, yes, the dash ought to be as long as the radii of the earth's orbit and wanted to shoot myself' (Kierkegaard, 460). The experience of an extreme high at a party followed by intense, suicidal misery seems akin to the metaphor of the insect that dies after fertilization. The retrospection used in recalling this emotionally high and low event thus form a third emotion regarding the event, one which is predominantly sardonic, looking back at the event with irony and general distaste which results in mockery. This emotion does not only mock the party, though there is an almost tangible contempt in his recalling of it, but also mocks the despair that followed the event with its joke about the long dash, making the despair seem almost puerile. Thus, within this isolated event, these different emotions oppose each other as they occurred in a linear succession: joy is opposed by despair; the joy and despair are opposed by the comic.

One more example of the thematization of contradiction in the text: Author A says, "Generally speaking, the imperfection in everything human is that its aspirations are achieved only by way of their opposites... (the melancholy have the best sense of the comic, the most opulent often the best sense of the rustic, the dissolute often the best sense of the moral, the doubter often the best sense of the religious) ..." (Kierkegaard, 20). Here Kierkegaard presents different examples of particulars who are composed of inherent, diametrically opposed traits that define characteristics of the individual by their internal contradictions. To stick with the theme of emotions, take the example of the melancholic having the best sense of the comic. Some people suppose "the outer" to be "the inner." A person who holds this supposition would assume a comedian is, in some way, always joking, laughing, and living within the comic. To those who suppose the inner and outer to be synonymous, the irony in the likelihood that the comic may, in fact, be melancholy outside of his comedic routine may be a befuddling truth. Yet such a contradiction is often the case! Internal contradiction of emotion does not solely negate the contradicting emotions, but rather constitutes the person of both disparate emotions. Internal contradiction makes one both and neither-the comic-melancholic, the something other which arises out of the contradiction.

With this is mind, emotions do not necessarily contradict only as time carries onward and experiences settle and change through their repetition in our memories. The generally accepted schematic of emotions suggests they function as discrete categories which rarely overlap and are easily definable (e.g., one can be happy, sad, angry, etc.). Yet this view appears to be mistaken, as it is possible to be stuck between contradictory states simultaneously in one experience. Author A provides a poetic image for this distinct experience: "I seem destined to have to suffer through all possible moods, to be required to have experiences of all kinds. At every moment I lie out in the middle of the ocean like a child who is supposed to learn to swim. I scream... it is an appalling way to gain experience" (Kierkegaard, 31-32). There is a kind of terror in being subject to all possible moods, as if one were always at risk of drowning. The experience of all possible moods goes 
beyond the internal contradiction met with two opposing moods, such that one does not merely experience sadness within happiness, anger within laugher, or the comic within the melancholic. One experiences any and all of these contradictory emotional states simultaneously to varying degrees of severity and is always subject to this fluctuating multiplicity of moods.

These moods need not be diametrically opposed to contradict one another, either: the various moods experienced merely need to be different from one another in order for this experience of an internal conflict of emotions to arise, for within difference arises contradiction. To be able to distinguish between two things requires that one seek out a contradiction in their relation to one another, however alike they may be. Thus, much as melancholy and joy oppose one another, melancholy and sadness oppose one another, though this opposition is subtler and requires additional explication. I wish to use the color wheel and the primary colors as an analogy to this understanding of difference. Consider how blue is opposed to yellow and red on a color wheel. Such contradiction is obvious, but in such contradictions arise new colors rather than a negation of the opposed terms. Further, given the color palette is something like a continuum, distinguishing any one color from another requires a recognition of the difference between the two which seeks out the ways in which the two respective colors may not fully cohere, ways in which the two are not one another. If one were to compare two greens and discovered one green had more blue in its composition than the other, which, say, happens to be composed more of yellow, the contradiction is found between the two--that one is composed more of blue while the other more of yellow, despite the colors both being green. This maps directly onto emotions if we are to concede that emotions, too, are more akin to a continuum than a rigid schematic composed solely of primary emotions. Author A, like Pascal, shows us that the "lie" which we are nothing but is not deliberately a lie, but a consequence of the complexity of emotions which are compounded by contradiction. Kierkegaard illustrates how Pascal's "lie" is a result of the presentation of ourselves to the world, our hasty resolution of the complexity of our emotions, our pseudonyms. To return to the juxtaposition of melancholy and sadness, one finds their difference in the fact that sadness is, tautologically, simply the state of being sad (a kind of primary or fundamental emotion) while melancholy is a more complex iteration of the fundamental sadness from which it emerges; the former is a primary color as the latter is a secondary (or tertiary, etc.) color. Each emotion would require particular relationally derived definitions that distinguish them from one another in order to properly make these contradictions clear.

The text of the Diapsalmata performs this multitude of emotional contradictions through its disordered aphorisms. In one aphorism, A is lamenting; in the next, he is intoxicated with joy from the sounds of a reed-pipe in the street (Kierkegaard, 41-42). This contradiction between emotions also occurs within the aphorisms themselves. In one aphorism, Author A is briefly in a state of contentedness until he is disturbed by a sense of longing: "The sun is shining brilliantly and beautifully into my room; the window in the next room is open... The air is so warm, and yet the whole city is as if deserted. --Then I call to mind my youth and my first love--when I was filled with longing; now I long only for my first longing" (Kierkegaard, 42). Not only are two different emotions experienced here, but the way in which they emerge from one another provides further insight into their relationship. While the contentedness experienced prior to the longing 
is more implicitly expressed than the longing which follows it, it acts as a grounding in the present which provides a ground for the wandering thought which leads A from contentedness to longing for his first longing. If, in the context of the quote, A were solely longing for his first longing, the way in which the emotion arose would be unknown. However, given the contentedness which preceded it, the longing, in its difference from contentedness as a perturbing desire and its emergence from contentedness, is grounded in contentedness. It contradicts the contentedness from which it emerges, yet in it inheres an element of contentedness, in that it is partially constituted by a privation of the contentedness which preceded it. This movement also adds to the definition of contentedness in this context insofar as it is defined, in part, by what is not longing, so long as we know that longing is what emerged from it. Thus, in their contradiction, and in any contradiction of emotions, the difference of the two terms also gives rise to the way in which each respective term inheres in the other as its negated opposite.

From here I should wish to explain how this philosophy of emotions, as it is "performed" in the Diapsalmata, is a monstrous philosophy. It is monstrous in the same way Socrates suggests he may be monstrous in Plato's Phaedrus. Socrates says, "[I] accept the current beliefs... and direct my inquiries, as I have just said, rather to myself, to discover whether I really am a more complex creature and more puffed up with pride than Typhon, or a simpler, gentler being whom heaven has blessed with a quiet, un-Typhonic nature" (Phaedrus, 230a-b). To be monstrous is to be comprised of discordant parts. Typhon is a chimera composed of disparate parts from a disparate assortment of animals, not himself any one thing but a conglomerate of these disparate parts. Unlike Socrates, who may be more monstrous than Typhon or gentler and un-Typhonic, the way emotions arise and contradict each other in the Diapsalmata are as monstrous as Typhon himself insofar as the work is comprised of utterly disparate emotional states which cohere only in their very incoherence. Along with any one emotion which makes itself present in the Diapsalmata, therein resides all of the emotions it is not, and so the disparate parts are relationally defined by their not-being emotions other than the ones which they are-They are defined, in part, by what they are not. The multiplicity of these emotions also coheres into a singular unified subject insofar as they are all emotions experienced by Author A and are thus grounded in the experience of that particular subject. This amorphous self is, at least in part, comprised of a multitude of contradictory emotions.

Furthermore, this monstrous philosophy of emotions acts as a prefatory philosophy for the question of Being. In Kierkegaard's preface to Prefaces, through the pseudonym Nicolaus Notabene, he provides a long list of what a preface is. In an excerpt from this list, he says, "A preface is a mood. Writing a preface is like sharpening a scythe, like tuning a guitar, like talking with a child, like spitting out the window" (Kierkegaard, Prefaces, 5). This is to say that a preface is potential, anticipatory, and that it delimits whatever it prefaces. A mood, or an amalgam of moods, certainly delimit the way in which one acts in a given situation and the way in which one perceives the world. In Martin Heidegger's book entitled the Introduction to Metaphysics, he suggests the fundamental question of Being, "why are there beings instead of nothing?" arises through different moods. He picks three general moods from which this question arises: joy, despair, and boredom. He says, "In great despair, for example, when all weight tends to dwindle 
away from things and the sense of things grows dark, the question looms. Perhaps it strikes only once, like the muffled tolling bell that resounds into Dasein and gradually fades away" (Heidegger, 1-2). As this question looms during a fit of despair, the way in which the question is taken may vary. In the Diapsalmata, when such despair overcomes Author A, he makes recourse to a kind of nihilism. For example, in a particularly suicidal despair, Author A says, "How empty and meaningless life is. --We bury a man; we accompany him to the grave... we ride out in a carriage... we find consolation in the thought that we have a long life ahead of us... Why not settle it all at once, why not stay out there and go along down into the grave...?" (Kierkegaard, 29). This meditation on the burial of a man is haunted by an utterly defeated, despairing mood. As the question of Being looms over the situation, Author A resolves, in his despair, that life is empty and without meaning. This is not to dismiss Author A's conclusion as being merely derived from an unsavory mood and thus not worthy of serious consideration, but rather to show that the question of Being, as it arises from despair, is easily resolved as being empty regardless of whether it may actually be so. That the mood, as preface, delimits the possible answers to the question of Being should be of utmost concern and addressed more fully at another time.

The Diapsalmata is a text which acts as a performative philosophy of emotions and is monstrous in the contradictory emotions of which it is composed. The relations between each emotional state, as they emerge within different aphorisms and, on occasion, emerge from within the same aphorism, are related by the contradiction in their very difference. It is therefore possible to be constituted of a plethora of contradictory emotions at any given time. In these differences, particular emotions resemble what their emotional other is not, such that they resemble the negation of their other as well as the features which positively define themselves. Thus, there is a coherence in the incoherence of the disparate emotions presented in the Diapsalmata. This philosophy also has prefatory weight on the question of Being, insofar as the question of Being and perception of Being itself can be delimited by the mood through which one experiences an awareness of the nakedness of Being. Pascal's formulation that "we are nothing but lies, duplicity, and contradiction" carries more weight than we may wish to concede.

\section{ACKNOWLEDGMENTS}

I wish to thank my family and friends for their boundless love and support. I also would like to thank Professor Michael Stern for his invaluable guidance in my attempts to realize the thesis of this paper.

\section{REFERENCES}

Garff, Joakim. Soren Kierkegaard: A Biography. Translated by Bruce H. Kirmmse, Princeton University Press, 2007.

Hamilton, Edith, and Huntington Cairns. Plato: The Collected Dialogues. Princeton University Press, 1989.

Heidegger, Martin, et al. Introduction to Metaphysics. Yale University Press, 2014. 
Kierkegaard, Soren. Either/Or. Translated by Howard Vincent Hong and Edna Hatlestad Hong, Princeton University Press, 2009.

Kierkegaard, Soren. Prefaces: Writing Sampler. Translated by Todd W. Nichol, Princeton University Press, 2009.

Pascal, Blaise, and A. J. Krailsheimer. Pensees. Penguin Books, 1995. 